\title{
DISCUSSION.
}

\section{ORGANIZATION IN PSYCHOLOGY.}

The demand for organization in psychology arises out of a dual interest. First, there is that of the teacher who desires to give a continuous account of his subject; second, that of the student, who would satisfy logical and xsthetical demands for unity.

One of the greatest difficulties that the teacher of psychology meets in the pursuit of his vocation is the almost total lack of plot in the average text-book. One could wish that the several chapters of the text, while serving to elaborate the general theme through the analysis of some particular character, might make the various characters so interact in the successive scenes as to stimulate interest in the development of the theme as a whole. Under such circumstances the psychologic story would move as it does not now. The sense of continuous movement, of interesting development of the theme, of a unified resultant conception in which the manifold analyses of the argument synthesize into an intelligible whole, is one difficult to bring to consciousness in the student. This difficulty, $I$ believe, finds its main source not in the inaptitude of the student to the subject nor in the unpedagogical methods of the teacher, but in the text and in certain transitory conditions of the science itself. As I have indicated the text lacks plot and plot interest. Plot demands that the characters function one with another in a continuous movement. Each, while playing its own part, must be other, sufficiently, to suggest that there is an inclusive whole, an immanent unity. In such circumstances curiosity, that universal principle of interest, asserts itself instinctively. Suggestive parts and elusive whole reciprocally stimulate and support one another. The theme lives in an ever-increasing interest which is satisfied only when it is fulfilled in the denouement. Now can we assert, fairly, that text-books in psychology have, as a rule, met these demands and realized this interest? I think not. Few are the psychologies that arouse and maintain a powerful interest in the average student. However intensely they may excite his interest in detail they fail to carry him along with increasing momentum. His enthusiasm attaches to parts and not to the whole. Frequently it is difficult for him to realize that a whole is intended. The rolume is a series of 
chapters dealing with individual topics, conjoined but not organically united. As to plot - it is rare. Conjunction of parts is not plot; nor is every arrangement, even though it be according to a defined scheme. Plot demands a principle of movement which is immanent and dynamic in the parts, as well as parts each of which after its own kind and in its own degree consciously exhibits the movement of the principle. Now, how frequently do we find a single unifying principle consciously presented as a clue in the opening chapters of our psychologies and wrought thoroughly to the end? How often do the val ious chapters look beyond themselves revealing traces of antecedent conditions and opening up vistas of subsequent circumstances determined by their own movement? Can one hold as a truth concerning our text-books that, as in well-wrought pieces of literature, the chapters mutually assist one another and consciously acivance the movement of a unifying theme? The majority of our psychologies are written from the standpoint of psychophysical parallelism considered as a working hypothesis. This, in itself, is fatal to all attempts at plot. Of every fact we have two descriptions and for every change we have two explanations. And this the student is quick to perceive. The separate stories cannot be woven into a single plot. Interest is divided and in division tends to lose itself. Were the study unified according to the tenets either of materialism or of spiritualism it could have a plot. In the former case the resultant conception would have tragic consequences for ethical presumptions; in the latter, the implication might appear to have a relation to the practical world similar to that now accorded to 'castles in Spain.' Nevertheless, there would be unity of organization and plot interest.

Furthermore, this desirable end would be attained also if the viewpoint of psychophysical parallelism were transcencled and a working hypothesis substituted for it which would regard the distinction between physical and mental as functional and not as existential. Curiously enough, such unity of organization as exists in most psychologies falls mainly upon the physical side. We can unify nervous structure in terms of neurones and nervous function in terms of instincts and habit. We can trace their groupings and organizations to a very considerable extent. On the mental side a similar unity has been aimed at but has not yet been attained. It is common tradition that ever since faculty psychology received its coup de grâce at the hands of Herbart the science has moved forward steadily upon the assumption of there being unity in mental life. But it is one thing to be conscious of the actuality of such a unity and another to exhibit its inma- 
nence through the organization of its parts. Doubtless it was natural that the developing science should center its interest in structure and in detail rather than in function and in the whole. Observations had to be made and observation means isolation and detail in work. Transitive activities had, in a sense, to be arrested, and such arrest resolves function into structure. Now, such piecemeal analysis, how ever necessary it may be, has the disadvantage that it does not conduce to exhibiting the vital interreaction of factors. On the contrary, it necessitates the substitution of a dissected body for the original organism. No matter how thorough the dissection and how clever the classification of the parts, they are none the less disjecta membra and must fail to exhibit the functioning of parts within a whole. This is the reason, I believe, why so many of our psychologies lack plot. Psychology has, in the main, been structural and not functional. Thorough studies and analyses of mental processes have been undertaken and carried through. The results have been registered and classified. But there has been an almost complete lack of such functional organizing of these results as would stimulate curiosity with reference to their interplay and would exhibit their interaction as well as the manner in which they are unified in their ground, the self. This isolation of parts, this lack of organization in the whole, forces itself upon the student and stands in the way, alike of his comprehension of the subject and of the developinent of an inclusive interest in it. He may be interested intensely in specific topics, but is keenly conscious of a marked hiatus in passing from one topic to another. This is true even of that God-send to teachers, James's psychology. The student's interest in it is of the episodic and not of the dramatic variety. He is charmed and enthusiasm is awakened in him in unique fashion by each of the successive chapters. But there is no denouement in the revelation of an organic whole. And what is true of James is true generally. The fatal hiatus existing between the contents of the successive chapters of structural psychology must exhibit the paradox of assuming an essential unity which its own method conceals. The truth of this contention is proven by the fact that symptoms of a definite change of view-point may be discerned in recent writings. This applies especially to the later writings of Baldwin, to certain portions of Miss Calkins's work, to the underlying method of the contributions of Dewey and Royce, to say nothing of others. But it has remained for Professor Angell to make the change consciously and to apply the new method with characteristic thoroughness and lucidity in a systematic work His volume has a 
marked plot interest and is functional to the core. Not only has he a single theme - that of the interaction of the psychophysical organism with its environment - but the successive chapters, while portraying their own distinctive characteristics, contribute each to the natural development of the theme and are constantly illuminated by the light cast upon each by every other. As a consequence the argument unfolds with constantly increasing interest and moves steadily to a unified corclusion. It is almost superfluous to recite that the volume appeals strongly to the student. Among my own pupils (the full Junior class of the college -150 strong) it is held by all in equal favor with James and by many in greater favor. It is the only psychology that I have yet been able to place side by side with James without remarks disparaging to the newcomer being made.

As, for pedagogical purposes, there is a grave lack of plot in psychological treatises, so, also, for theoretical purposes, there is a similar lack of system. Ordinarily, no unifying conception is propounded at the beginning and its validity demonstrated through the progress of the investigation. There is no theory which defines psychic functions individually and also correlates them into a systematic whole. The nearest approach to this requirement has been made from the standpoint of physiological psychology. The hypothesis that every mental process has a physical basis or correlate has, without doubt, enabled the science to advance by leaps and bounds. But although we can, with moderate success, indicate the probable physical basis of the majority of psychic activities and can roughly schematize them, still two things much to be desired are lacking. First, the functional relationships of the varied physical bases have not yet been worked out; second, the knowledge of physical correlates in individual cases has not enabled the psychologist, in any marked degree, to bring mental functions under a single principle and to exhibit their organic unity. Moreover, even were these two requirements fulfilled the parallelistic hypothesis would still bar the way to unity as it has done in the past. So long as psychologists accept the psychophysical distinction as existential and not as methodological so long nust they bid farewell to claims for systematic unity in their science. That psychologists, quite generally, accept parallelism as a working hypothesis will scarcely be doubted. It is an obvious inference that the science must exhibit a fundamental dualism.

Aside from this, psychology lacks organization in the arrangement of its subject matter. Suppose we take the well worn general divisions into intellect, feeling (affection) and will (conation). Is not this 
a survival from a pre-scientific age in psychology? Is there any rational motive for treating intellectual functions first, affective second, and conative last of all? One might question whetluer placing the entire system of intellectual activities in the forefront of a psychological treatise is consistent either with the instrumental, pragmatic function ascribed to intellect as at least one of its critical phases or with a sort of spiral movement attributed to psychic functions in this development by the so-called circular reaction theory. Again, is not the position assigned to affection out of touch with the theory that emotion is the immediacy of our consciousness of the tension constituted by the clash of instinctive (and habitual) activities in misadjusted activity? This point is emphasized further by the theory that it is out of just such tensions in action that the mediating intellectual function arises and that it plays the rôle of opening up the way to a possible reunification of activity.

Again, we may ask, is the order of topics in psychological treatises indicative, as a general thing, of any ascertainable principle of organization? Has the semblance of order any more definite basis than that similar functions are usually classed together, that a certain endeavor has been made to place the complex after the simple and the reproductive after the original? At critical points the arrangement is anomalous, a fact sufficiently indicative of the absence of a thoroughly organized arrangement. For example, if instinct plays such a fundamental rôle, with reference to all conscious processes, as we are now coming to believe that it does, it is a curious arrangement that delays its appearance upon the scene of mental development until a very late hour. Habit, also, although it plays a part equally important with that of instinct, does not appear to have any well defined position of its own. Attention is gradually gravitating toward a position in harmony with its prominence as an intellectual function. The fate of interest and of belief, however, has been sad. Their lot - bandied ahout as they have been from point to point, when they have not been overlooked entirely - is worse almost than that of lost souls in Fades. Finally, the position assigned to the self in such a treatise as that of James, would seem to be conspicuously out of place. If the concrete self be the sole psychic reality one would expect that its consideration would furnish the grand conclusion in which the master-word would be spoken and all previous considerations unified in the presentation of the final all-embracing fact.

The lack of system is illustrated perhaps as fully by the omissions of individual psychologists as by any other circumstance. There 
appears to be no common ground comprehensively covered. It will suffice, in proof of this, merely to call to mind the presence or absence in individual texts of such topics as interest, desire, belief, ideals, imagination (in distinction from the treatment of varieties of imagery).

If we view these facts together I believe that we shall be convinced that the time has come when structural psychology must pass definitely into functional psychology and when a unifying principle must be sought for the organization of mental activities. Furthermore, this principle must transcend the dualism of parallelism. For just so long as we work intelligently upon the basis of this method we must emphasize diversity and not unity. Yet every science must aim at the unification of its data. Either, then, we must admit that physical conditions are inessential to psychology or we must endeavor to transcend the dualism of psychophysical parallelism. Now I do not intend to enter upon a serious discussion of psychophysical parallelism at this juncture. Nevertheless, one may point out certain peculiarities of the hypothesis which may suggest the manner in which it is to be transcended. These peculiarities may be summarized as follows. The doctrine contradicts itself or, otherwise, the distinction and the parallelism asserted by it have merely methodological and functional values. If we regard the distinction of physical from mental as grounded in an existential separation of processes and then take parallelism seriously the theory lands us in absurdities. It presupposes what it must deny. We contrast the two processes and consequently must have knowledge of each. I'et, if there were an exclusive paraltelism our psychoses should be totally and eternally unaware of, as well as uninfluenced by, their parallel neuroses. Our contrasting of the terms would indicate that they had a common basis; the parallelistic character attributed to them would suggest, further, the idea that a single process was under description, that a single fact was being read now in one set of terms, now in another - hence the marvel of the parallelism. Finally, their apparent duality for consciousness would indicate a polarity of function and not a dualism of process. Hence the real problem is to ascertain under what conditions and in what circumstances this polarity arises, its method of operation and its significance in the development of organic activity. To determine this and to utilize the insight as a clue to the organization of his science is the fundamental problem of the psychologist. The further question, as to how the quantitative values, to which the physical is most naturally reduced, are related to the qualitative of the psychical is one that falls within the primary problem in psychology as it does 
within many others. No doubt it is of vast importance but after all it has no more special application to psychology than to physiology, biology and, chemistry. Indeed, it is essentially a question of pure methodology, viz., the part which mechanical and quantitative formulations play in the exact description, measurement and control of qualitative processes.

The unifying principle, therefore, that psychology demands is one which accounts for the polarity of the psychical and the physical functionally and which recognizes in them describable movements of a single organic process. It must enable the psychologist to use both methods of description in an entirely natural manner, to indicate how the single activity is modified now in terms of one phase of its movements and now of the other.

Now just as Professor Angell satisfied the demands of plot interest on the pedagogical side, so theoretically, he fulfills the primary denands of system. Iis psychology centers in a single unifying principle whose ramifications and bearings are exhibited at evesy turn of the argument. As a consequence the treatment is highly illuminating. The chapters do not follow the outworn arrangements of other days or by accident fall into a certain order. Each has a definite and noticeable position in the elaboration of the central theme and exposes in its own movement an individual characteristic of the unifying plot.

This principle is his conception of the psychophysical organism and the development of its conscions life through the solution of the practical problems set it by the necessity of constantly adjusting its activities in the presence of a changing environment. Although this biological standpoint ${ }^{1}$ is not original with Professor Angell but is the expression of a dominant tendency in current psychology, nevertheless his thorough functional application of it is decidedly novel and original. His emphasis of the point of view and his consciousness of the necessity of system in psychology has opened up the way to an entire re.writing of the subject.

I shall next attempt to emphasize the necessity for organization by a brief outline of psychologic functions as this is determined by tracing out the clues furnished by the biological conception.

The biological conception, as I understand it, holds that the distinction of physical and psychical - of body from mind - is not one of which we are continually conscious. Under ordinary circumstances

${ }^{1}$ Especial recognition is due Professor J. M. Baidwin for his distinctive work in 'setting ' the hological tendency as distiuct from the physiological; see his Mental Dezelopment and Dezelopment and Evolution. 
and in so far as our organic activities operate smoothly our experience is single. Individuality, qualitatively appreciated, is that of a continuous stream of activities unified as a single reality. When, however, this vital activity experiences inhibition within any phase of its movement tension arises and at once the distinction of physical from psychical emerges. In this tension of vital activities we locate the physical as that phase of the complex which serves as the dynamic base or support of the necessary adjustment. The psychical is the phase in which the adjustment is constituted. In so far as the adjustment is completed and perfected tension disappears and vital unity re-asserts itself. In further readjustments of activity the form of organization gained by previous adjustment appears as an integral part of the basis, $i . e$., on the physical side. Now we apply the term instinct to native coordinations and habit to those which are acquired. Thus we may say that the distinction between physical and mental arises out of the reorganization of functional activities in which the tendencies toward the persistence of the native base are denominated instinctive; the tendencies toward reorganization - the psychical; the completed coordination, itself - serving as a basis for further adjustments - the habitual. Hence instinctive adjustments of function take on the form of the psychical and the complete organization of the psychical emerges as habit. Generalizing, therefore, we may say that the instinctive and habitual bases of organic development constitute what we designate bodily function; that the momentary reconstitutive adjustments comprise mental function: that the distinction is entirely functional and that the unitary living organism is the sole individual. It would appear necessary therefore that an exact treatment of the characteristics of instinct and habit and of their relation to psychic function should be given early in any general treatise upon psychology. Such a treatment would naturally lead in two directions. First, it would initiate such a general chapter upon the nervous system as is ordinarily given and which would serve as a basis for the special treatment of the physical functions which constitute the bases of mental activities in individual organic adjustments. Second, it would emerge in a chapter dealing with the general characteristics of psychic activities such as James treats under the title 'Stream of Consciousness.' This should emphasize the momentary and individual character of mental states, the unity of successive psychic streams, their discreteness, the organic and functional conditions alike of the discreteness and of the continuity which they exhibit, the focalizing power of the stream - with the conditions of its operation and direction, its discriminating and correlat- 
ing moments with their organic motives. Moreover, such a chapter should also adjust the relations of the intellectual, feeling and conative phases of psychic activity in accordance with the clue furnished by the primary conception of the psychophysical relation.

According to my own notions this adjustment would take the following form. States of feeling should be taken first in order of treatment ; intellectual states, - second ; and conative,- third. ${ }^{1}$ My reason for this arrangement is the following. In any adjustment involving tension the phase of psychic function directly evoked is that of feeling whether as sensibility, emotion or icleal. The organism, as it were, turns out as immediate appreciation its own inner value or quale. This view is supported in the extreme by the prevalence of intense sensibility in cases where nervous forces are strained to the limit and where the organism cannot, immediately, bring the irritating conditions under control; by the prevalence of emotionalism in the period of adolesence; by the emphasis upon feeling when old habits (e.g., belief) have been broken up and when new methods of action have not yet been defined nor put into operation. Feeling, in short, is the phase of organic activity wherein an oid coördination is undelgoing strain or disintegration and where it has not yet got itself sufficiently in hand to define its own position or to control it. Conformable with this is the fact that in phases of activity where feeling predominates we look neither for defined views nor for effective action. They are states of confusion. The moment, however, the organism masses its activities positively and proceeds to the examination of its own condition for the purpose of overcoming the inhibition, feeling passes into intellect. Herein discrimination and correlation, leading to explicitness of definition, expose themselves. When definition has been completed, conation supervenes and the basis for a new phase of habit is established. Each phase of psychic activity may occupy a shorter or a longer period of time or its natural course of development may be aborted but wherever adjustment fully asserts itself feeling arises on the basis of instinct, defines itself as intellect, establishes itself as conation and emerges as habit. In further adjustments the gains made assert themselves as physical basis, $i$. e., as habit-instinct, coördinations. As such they furnish material for richer appreciations as feeling, for fuller definitions as intellect and for greater effectiveness as

I However, as will be seen in what follows, this does not mean that fecling should be treated in its entirety before any investigation of intellectual and conative states is made. Only, that on any given 'level' it is more natural that fecling should precede intellect aud conation. 
conation. Consequently the chapter on the stream of consciousness should close with an elaboration of the circular reaction hypothesis of organic activity as a fundamental principle for the more complete understanding of the interrelation of the physical and the psychical and of the concrete development of our experiences in their totality.

Psychologists as a usual thing pass from such a general chapter as we have described (i.e., if they insert it at all) to the detailed treatment in turn of the entire list of functions exhibited by each of the phases of psychic activity. For example, - attention, sensation, perception, memory, association, iniagination, and reasoning are treated fully before any states of feeling are examined and these in turn before the conative field is explored. This procedure, it seems to me, is erroneous. It makes an organic treatment of psychology impossible, inasmuch as it takes each one of the phases of psychic activity out of its functional relationship to the other two and from within the organic movement of which it is a phase. If the intellectual function can be understood only in relation to fceling and to conation is it not essential that we should examine sensation and perception with reference to feeling on the one hand and to conation upon the other? In other words, is it not necessary to treat functions of the same level of simplicity or complexity in their natural order and relationships as phases of a single movement before passing from a lower level of complexity to a higher? Shall we not gain a better understanding of the individual states themselves and of the psychic activity of which they are phases if we examine sensibility, sensation and perception, impulse on one level; emotion, memory and association, character (so-called conscious habit - a misnomer) on another levei ; ideals, imagination and reasoning, volition on the third and highest level. The theory back of the classification is that the phenomena of any given level are really one fact considered in several phases. Organic adjustment, if taken in its most individual and most momentary function, constitutes itself as sensibility, or as sensation and perception, or as impulse according to the stage at which it is taken. A similar identity of function will be found to operate in the more complex groups of phenomena, the distinguishing differences within each being accounted for by the form of the total reaction constituting the several phases of the common movement. Having introduced simplicity into the treatment of phenomena upon the same level it remains to be noted in this connection that a like simplicity can be introduced into the treatment of the relations of the different levels one to another and to the total psychic movement. Here we avail ourselves of the light cast upon organic 
development by the circular reaction theory. It was noted above that the psychic phase of organic activity tends, as the adjustment is more fully accomplished, to pass over into the physical phase of activity. From this, an occasion of further adjustments, it passes into richer, more defined and more effective forms of psychic activity. Thus every moment builds itself into the organism and exhibits traces of its effectiveness in the development alike of physical and psychical function. Accordingly, in emotion, in memory and association, in character we trace the continuity of organic life. In emotion, feeling no longer presents itself in the simplicity of sensibility, but modified by the articulation and enlargement of the total organic activity. The tension which in sensibility was confined to a relatively simpler complex of coordinations involves in emotion ever larger groups until, on occasion, the whole organism may be in reverberation. Thus momentary feeling becomes infused with the consolidated gains of the psychophysical organism, or at least such of them as its quality appropriately evokes, and as these are incorporated into it in the form of affection. Memory and association, as also character, exhibit the direction of similar organic mediation, the one in terms of the intellectual phase of psychical activity, the other in that of conation.

On the level where ideals, imagination and reason, volition play their parts in a self-conscious medium, mediation takes on the form of development in terms of ever more complete organization. The entire organism tends toward articulate and complete self-expression. This organic self-expression, developed through tension and appearing in the immediacy of feeling, constitutes the ideal within us. Defined as intellect it takes on the forms of our life of imagination and reason. Operative again as conation it is our voluntary behavior.

Certain peculiarities of this scheme of organization are to be noted. I believe that some attention to these will give added force to the general arrangement. First, it will be observed that psychic functions in their intellectual phase arrange thernselves in pairs. That such an arrangement is natural is shown by the fact that it has been found impossible to give an account of one member of any of the three pairs without involving the other. Sensation cannot be treated without reference to perception or vice versa. And the same thing is true of memory and association, as also of imagination and reason. The situation simplifies itself when we observe that in these three pairs of terms we have the developmental history of a single pair on three levels. The single pair are the image and the idea. What is meant is that sensation, 
memory and imagination are functions whose essential feature is the psychical image, whereas perception, association, reason have as their essential feature the idea. Now just as the members of the several pairs were indissolubly united so also are the image and the idea. They are distinguishable but not separable moments of the intellectual phase of organic adjustment. The image is ever the aspect of the adjustment in which the material of reorganization is defined: the idea that in which the material is correlated into a definite method of reconstruction. The one is analytic, the other synthetic. The life of feeling which provides the motive for intellect is single because undefined; the life of action - the terminus of the intellect - tends toward singleness because it has been defined; intellect is dual because in it the material and method of adjustment is being defined. Second, it will be noted that three important psychic phenomena are missing from the scheme. The three are interest, attention and desire. It takes no great insight to discern that these are functional centers to the three great phases of psychic activity. In other words, interest is feeling observed in its essential principle; attention is the intellect in principle; desire in itself is conation. Sensibility, emotion, ideals as forms of feeling are phases of interest. It is the unifying principle of which they are the concrete circumstantial manifestations. The same thing is true of intellectual states with reference to attention and of conative states with reference to desire. Once more we are brought back to the thought that feeling, intellect and conation are distinguishable only by their functions, for interest, attention and desire are the same active principle of adjustment taken now in its appreciative phase, now as definitive, and now again as executive. Moreover, this point is emphasized by the fact that even as psychic life is a unity, so its fundamental principles of psychic organization unify themselves in a single function - belief. In belief we find the fundamental principle of psychic organization. It is the common denominator and focal principle of interest, attention and desire. Operating as faith, it is the control center of feeling, i. e., it is interest; as conviction, the control of intellect, it is attention; as practice, it is the essence of desire.

These considerations lead naturally to the final factors in psychic organization - the subject-object consciousness, time and space perception, and the self. When examining into the problems of psychophysical values we discovered a single fact - organic experience which was thrown into contrast by the presence of inhibition and consequent tension. In taking into consideration the further fact of or- 
ganic readjustment we were led to the identification of the physical with the forms of coordination (instinctive and habitual) which were sufficiently fixed to serve as bases in the reconstruction. The psychical was identified with the movement of adjustment itself. If now we take into account our fullest organization of the base of organic adjustment we describe the function as body, the immediately defined object in experience. If, on the other hand, attention be directed to our fullest organization of organic adjustment we describe the function as mind, the immediate subject in experience. The larger vista opened up by the interaction of the organism with the environment is the world of experience. It is not difficult, therefore, to see that the treatment of space-perception should give definite form to our view of the object both as body and as world, whereas the treatment of temporal perception should round out the subject of experience and should deepen our conceptions of the object. There remains the self. If we bear in mind that body and mind, object and subject, are but functional phases of organic activity, we are led to the conclusion that the unitary experience which is ourselves is to be identified with our total organic activity. Thus the self originates as organic activity, develops itself through tension and adjustment as body and as mind, and perfects itself in those forms of effective self-conscions activity in which the distinction of subject and object has been merged in the self-consciousness of free adequate function.

If this analysis be correct the problem of arrangement of topics in psychological treatises becoures relatively simple. It would seem natural that the general chapter upon the stream of consciousness should be followed by the treatment of the fundamental principles of organization in feeling, intellect and conation, $i . e$. , with interest, attention and desire in their general relations one to another, and to the development of psychic life. This would lead naturally to the treatment of sensibility, sensation and perception, impulse as phases of a single movement and with constant reference to their physical basis. Next, the growth of physical and mental functions should be traced in emotion, memory and associatien, character. After this would follow a similar treatment of organic development into its free creative forms as ideals, imagination and reason, volition. Such a treatment would naturally lead to a general unification, first, on the side of principle, and second, on the side of concrete content. The first would emerge in the examination of belief as the unification of interest, attention and desire, as also of its elaboration in complexity, range and freedom through the development of psychic activity into ultimate creative 
form. The second would emerge, on the one hand, in the study of the problem of space-perception as unifying our conceptions of the object in experience, and, on the other hand, in that of time-perception as unifying our conceptions of the subject in experience. Finally, our entire study should unify itself in the thorough investigation of the self as it manifests itself through the various stages of organic development.

Thus pedagogical and theoretical interests alike emphasize the necessity for a more complete organization of psychology than is found at present. The central principle of such organization must be biological. Its application must be natural and organic. Psychological treatises must refuse even formal recognition of pre-scientific divisions and must adopt such an order as conduces best to the exhibition of that development upon whose actuality they insist. By such procedure we may hope that in the future psychologies may be enabled to reflect in their structure and movement the organic unity of the life which they describe. ${ }^{1}$

OBERIIN COLLEGE.

S. F. MacLennax.

1 The MS. of this article was received December I3, 1905. - ED. 